\title{
Address of the editor team
}

\author{
Thomas Brenner · Georg Hirte
}

Published online: 14 August 2015

(C) Springer-Verlag Berlin Heidelberg 2015

The Review of Regional Research (Jahrbuch für Regionalwissenschaft) has undergone a number of changes since one of us (Georg Hirte) became the new editor 2 years ago: the switch to the English name, the use of the Editorial Manager, the new international Editorial Board, and the much broader listing of the Journal (Scopus etc.). It is now time to make the next move. For this reason the Board of the Gesellschaft für Regionalforschung (GfR)-the German speaking section of ERSA/ RSAI-decided to invite the second of us, Thomas Brenner, Professor for Economic Geography at the Philipps-University Marburg, to join the editor-in-chief team of the journal.

It is now our joint task to establish the Review of Regional Research further in the field of regional science and surrounding areas. While the authors of most of the so far published papers have an economic background, we want to strengthen the interdisciplinary scope of the journal and expand this community to other fields, in particular, to economic geographers.

The general policy of the journal will not change: Contributions from the fields of economics, economic geography, sociology, planning, transportation science and environmental research will be welcome if their focus is on regions or cities. We encourage authors to submit English written papers, but following the rules of the German speaking section (GfR) papers written in German will still be welcome. However, if a paper is of interest to an international readership we will ask the authors to translate the paper into English. Papers shall follow scientific standards in their

\footnotetext{
T. Brenner $(\bowtie)$

Philipps-Universität Marburg,

Deutschhausstraße 10,

35032 Marburg, Germany

e-mail: thomas.brenner@geo.uni-marburg.de

G. Hirte

Technische Universität Dresden,

01062 Dresden, Germany

e-mail: Georg.Hirte@tu-dresden.de
} 
specific subfield and it will be possible to publish contributions that apply already known studies to other countries, regions or reproduce them with new data. We also encourage authors to submit surveys on important topics in the field.

From time to time we want to publish special issues. Proposals for future special issues are welcome. The last special issue was on Universities and the Region in 2014 for which we like to thank the guest editors Rüdiger Hamm and Johannes Kopper. Rüdiger Hamm is also guest editor of this issue invited to handle the paper submitted by one of the editors.

During the last 2 years the editorial board provided invaluable support. The members of the boards supported us in acquiring good papers, reviewing submitted papers and suggesting reviewers. We appreciate this help and also the warm welcome Thomas got from the board members. We in particular thank the Springer team, and also all authors, reviewers and readers for supporting this Journal.

It is a challenge and pleasure to be responsible for the Review of Regional Research. We will do our best for this journal because we are convinced that there is a need for decent journals that fill a niche below the small number of top field journals.

Marburg and Dresden, August 2015

Thomas Brenner and Georg Hirte 